\title{
Designing and Preparing the Development Model of Marketing in Volleyball Super League of Iran
}

\author{
${ }^{1}$ Siavash Khodaparast", ${ }^{2}$ Seyed Mohammad Hossein Razavi, ${ }^{3}$ Morteza Rezaee Soufi, \\ ${ }^{4}$ Ali Mohammad Safania \\ ${ }^{1}$ Department of Physical Education and Sport Sciences, Lahijan Branch, Islamic Azad University, Lahijan, \\ Iran. ${ }^{2}$ Department of Sport Management, Faculty of Sports Science, University of Mazandaran, Babolsar, \\ Iran. ${ }^{3}$ Payame Noor University, Rasht Iran. ${ }^{4}$ Department of Physical Education and Sport Sciences, Science \\ and Research Branch, Islamic Azad University, Tehran, Iran.
}

Submitted 20 February 2019; Accepted in final form 13 May 2019.

\begin{abstract}
Background. Marketing is essential for any kind of conscious movement in today's market; a market that no longer recognizes either the borders or a particular customer. Objectives. The aim of this research is designing and preparing the development model of marketing in volleyball Super League of Iran. Methods. The current research is an applied one from the point of its aims. The research method for this study is mixed methods research of the discovery serial type. At the end of this stage, important factors contributing on the designing and preparing the development model of marketing in volleyball Super League were used. The population for this research included general managers, leaders, managers, and coaches present in the super league of Iran. The sample including 102 members was chosen based on theoretical sampling method using the Cochran formula. The research tool for this paper was a questionnaire consisting of 139 two-way 5-option questions. In order to test the hypotheses Lisrel and SPSS software were used. Results. The results indicated that in optimal circumstances, management, environment, strategy, partitioning the goal market, locating, and mixed marketing are influential factors in Iran's volleyball super league. Moreover, in optimal conditions, the priorities of the marketing variables of Iran's super league are management, environment, strategy, mixed marketing, target market, and locating. In the current situation, sport marketing management in sport marketing strategy and mixed marketing has a positive significant impact. Conclusion. In order to reach the above-mentioned marketing we should consider factors like management, environment, strategy, partitioning the target market, and contexts should be considered as influential factors.
\end{abstract}

\section{KEY WORDS: Sport Marketing Model, Marketing, Volleyball}

\section{INTRODUCTION}

In today's world, many changes are observed along with the spread of competition in a variety of fields, especially in markets. Marketing is essential for any kind of conscious movement in today's market; a market that no longer recognizes either the borders or a particular customer. The slogan of today's marketing for all entrepreneurs and managers and professional marketers is summarized in this short term: "Think on a world level, act locally." The globalization of markets means the economy and trade without borders which requires broad insights, targeted movement, system attitude, and enhancing capabilities and improving regulations and regulations. In such a dynamic environment, marketing has evolved as a holistic business

*. Corresponding Author:

Siavash Khodaparast, Assistant Professor

E-mail: s.khodaparast@yahoo.com 
philosophy to build relationships between organization and market.

One of the most important strategies for improving marketing and increasing income is having a strategic marketing plan and then operating this program. If sport managers pursue strategic marketing planning, they will be able to control the complex environment of sport industry and gain high economic benefits (1). Sport marketing is unique because its customers are not as buyers of other products. Providers of sport events or physical fitness due to "the free nature of activities", "the instability of events" and "the halo of ambiguity surrounding the results" cannot predict the salience of the work (2).

Marketing is a complex function and sport marketing is even more complicated because sport has certain features that make sport products unique. Sport has been able to find a very strong place among the people because of its specific attractiveness and comprehensive advantages including health, happiness, excitement, competitiveness, competence, fame, honor, and tens of unique products such as sporting equipment, food supplements, drinks, clothing and other sports products, and was easily ranked first among the industrialized countries in the world like the United States and the United Kingdom (3).

The presence of sports enthusiasts, sports contests, health and well-being fans who call for lean, fast and varied sports services have made sport known as a popular and lucrative industry with its mounting growth in all possible forms including entertainment, sports market, physical fitness, drugs, professional sports, especially in industrialized countries, which is ranked sixth in the world with an estimated value of 300 billion dollars (4). Volleyball is of one of the most popular sports, and with regard to research, it is very important with sports planners after soccer. It has attracted particular attention in different geographic regions of Iran, particularly in the northwest, northeast and central areas. In the last decade, given the full support of the Volleyball Federation, championship titles have been attained in the teenagers and youth tournaments at Asian and international levels, but the titles earned in different years were heterogeneous and unstable. In this regard, a number of research has been conducted which we refer to a number of them here.
In a research titled "examination of the impact of green marketing strategy on organizational performance in sport federations", it was concluded that all three green marketing strategies (green innovation, green promotion and green advertising) had a positive impact on the organization's performance (5).

The results of a $\mathrm{PhD}$ thesis titled as "analysis and modeling of the country's marketing mix of sport industry with decision- oriented approach" showed that eight factors contribute to the marketing mix of sport industry in the country. Among the eight factors, the factors governing the market, financial support, pricing management, and management of promotion and determining variables of each of the above four factors were identified as the independent variables for manipulating managers; two factors of process management and public relations management and determining variables were identified as mediator variables, and location management and index management were regarded as response variables in the model. It is also, for the following reasons, that the model has the highest proportion of fitness and efficiency with the country's sports data: (a) the model is built on an exploratory factor analysis and according to the expectation that it is the best fit with the country's sports data, and $b$ ) this model provides more information on the effects of the variables as compared to other models and because of the above-mentioned eight factors and by introducing more independent variables, it provides more management strategies (6).

In a research that assessed the sport marketing mix factor and its seven components (product, price, promotion, location, public relations, people and physical evidence) in the premier soccer league from the viewpoint of managers of physical education and soccer federation of the Islamic republic of Iran, it was concluded that concerning the subjects, marketing mix in the status quo and the desirable situation had no priority over each other. In addition, there was a significant difference between the existing and desirable status of sport marketing and its components in the premier soccer league. In general, in terms of the viewpoint of the officials of the organization of physical education and soccer federation, in the desirable situation, all marketing mix components should be noticed in the same way, as it is in the situation now, but the quantity or quality of attention in the existing 
situation is trivial compared to the desired condition (7).

Sport marketing requires professional and experienced marketers. The role of sport marketers in the development of marketing and the development of the championship sport is very important, and sport marketers are important players to make and use the financial resources of sport (8). Sport marketing in the UK, between 1992 and 2000, had an increase of $45 \%$ (9).

Marketing is a valuable means of ensuring good financial foundation of a team. Selling tickets is one of the most important ways to earn the revenue of clubs and sports organizations (10). Receiving the registration funds and the right to membership are the clubs' ways to earn money which should not be ignored (11). Also, in the outline of Document for Strategic Development of Physical Education and Sport (2002), registration funds have obtained an important role. In the outline of Document for Strategic Development of Physical Education and Sport (2002), it has been mentioned that sporting betting, although one of the most important marketing methods in many countries, is not known in our country as an effective way of earning funds (12).

The risks involved in expenditure and expense spent in sport and marketing are dealt with in another study in which the authors try to explore the importance of this subject and analyze the very high numbers spent in sports over the last years. It has been shown in this study that advertising has an important role in both costs and in revenues and increased product sales. In the literature, no similar study is not found to what the current researchers intend to do here. In Fact, in the most similarity, there are two to seven of the 20-cases of sport marketing intended by the researcher in this research. The researchers here intend to question twenty of the methods of sport marketing in two components of their existing and desirable status in Iran. The aim of this research is to design and develop the marketing development model of the volleyball super league of Iran (13).

\section{MATERIALS AND METHODS}

The current research is an applied one from the point of its aims. The research method for this study is mixed methods research of the discovery serial type such that the effective factors on the club marketing (service marketing mix) are used in structured interviews. The findings from these interviews have become a questionnaire in the next stage to determine the priority of these factors by using statistical methods. At the end of this stage, the important factors affecting the marketing of the super league clubs are used to develop the development model of marketing in volleyball Super League of Iran.

Participants. The population for this research included two groups: a) University individuals who were specialized in sport strategic planning and sport marketing. (These were selected using criteria such as the number of articles published in these fields), and b) Staff officials from the Ministry of Sports and Youth from the level of senior managers, volleyball federation officials, officials in the league, CEOs, leaders, managers, and coaches present in the super league of Iran, a total population of 130 individuals in the study.

In this study the theoretical sampling method (theoretical sampling is a purposeful sampling scheme which is used in qualitative research), as it is necessary to obtain data from particular individuals in this study, is used. 20 professors and experts who had a past in marketing and sports strategy were selected. In addition to 20 questionnaires that were received, 110 questionnaires were distributed among the statistical population, which resulted in 82 proper questionnaires, and in total, 102 questionnaires were the statistical sample of the research.

Tools. In the first part, some demographic characteristics of subjects including age, gender, degree of education, educational field, and background work were investigated. In the second part, a questionnaire consisting of 139 Likert 5-option questions associated with marketing was used. In order to value questions in the existing and desirable situation, very low, low, moderate, high and very high (scores 1 to 5) were used. The overall score of each field and its contents were used by the average of the items related to it. The content validity of the questionnaire was examined using the views of 13 leading professors and advisors of sport management of the universities of Iran. Also the internal reliability of the questionnaire was determined by Cronbach's alpha, which was equal to $82 \%$.

Statistical Analysis. The data obtained from the questionnaire were summarized using descriptive statistics methods (frequency, percentage, mean and standard deviation) in the 
form of table and plot of summary and classification. Then they were prioritized based on the average of each item. The KolmogorovSmirnov test was used to compare the distribution type with normal distribution.

Also, a single sample distribution test was used to investigate the importance of effective factors on marketing. The dividing criterion in this case was the hypothetical average (3). If subjects had given the relevant factor above 3 , it would be to attach importance to it, and if the mean was less than 3 , it was considered to be a minor factor for participants.

In this study, a factor analysis was used to investigate the integration of factors and their prioritization.

The first decision in the application of factor analysis is to compute the correlational matrix. To determine the coefficients of elements related to marketing variables, factor analysis was used to analyze the principal component in a basic concept. Factor analysis is one of the multivariate methods in which the independent and dependent variables are not considered, and its main purpose is to summarize the number of variables in a limited number of factors such that in this process, the least amount of information is missing.

In order to determine the adequacy of the sample in this method, the KMO test with the value 0.5 was used. In order to determine the suitability of the use of factor analysis and its validity, the Bartlett test was used at 0.05 level.
In this study, we used the path analysis method to make model and analyze it. The nature of this study is multivariate and cannot be solved by two variables, so a multivariate analysis is used. Also in order to analyze the different variables in a theory-based structure that show the simultaneous effects of variables, factor analysis and multivariate regression were used that in addition to the direct effects of the independent variables on dependent variables consider the indirect effects of these variables and introduce the relationships between variables in accordance with the realities contained in the analysis and analyze the relationships and correlation observed between them in logical terms.

For this purpose, exogenous variables and endogenous variables were determined. After that, the hypothesized theory was drawn up in the form of a theoretical structural model. In this model, the causal order was determined for causal relationships. Then structural equations were written based on causal assumptions. Then, these functional equations and relations with multivariate stepwise and least two-step regressions were tested and validated or rejected. Based on this analysis, the fit pattern was constructed based on experimental data. All of the analyses were carried out by SPSS software version 22.

\section{RESULTS}

The description of the demographic characteristics of the research samples is visible in Table 1.

Table 1. Demographic Features of Respondents

\begin{tabular}{|lcc|}
\hline Variable & number & Frequency percentage \\
Age & 22 & 21.6 \\
$41-40$ & 58 & 56.9 \\
$51-50$ & 22 & 21.6 \\
Gender & & \\
$\quad$ Female & 6 & 5.9 \\
male & 96 & 94.1 \\
Educational level & & \\
Associate Degree & 7 & 6.9 \\
Bachelor & 27 & 26.5 \\
master & 35 & 34.3 \\
Doctorate & 33 & 32.4 \\
Major & & \\
Physical Education & 69 & 67.6 \\
Non-physical education & 33 & 32.4 \\
Job experience & & \\
1-5 year & 15 & 14.7 \\
6-10 year & 22 & 21.6 \\
11-15 year & 25 & 24.5 \\
16-20 year & 16 & 15.7 \\
Over 20 years old & 24 & 23.5 \\
\hline
\end{tabular}


In studying the variables of the present study, the following results were obtained from the statistical analyses: Kolmogorov-Smirnov test was used to examine the distribution of variables in a normal way. The null hypothesis in this test is the normal distribution of the variable. If the significance level of the test is larger than 0.05 , the null hypothesis is confirmed and we conclude that the variable distribution is normal. Considering the significant levels obtained, it is concluded that all variables have a normal distribution (a significant level greater than 0.05).

The single sample t-test results show that in optimal situation, management, environment, strategy, segmentation-target market, positioning, and marketing mix are factors affecting the marketing of the Iranian volleyball super league (average of 3 and a significant level less than $0.05)$.

Also, the KMO index is equal to 0.87 and the significance level of Bartlett's spherical test is 0.001 , so it is concluded that the obtained data is suitable for the factor analysis and sampling is sufficient. In table 4, the coefficients of the factor loads of each of the marketing variables are given on the main factor obtained. As you can see, the priority of marketing variables of the super volleyball league of Iran in the current situation is the environment, marketing mix, strategy, segmentation of the target market and positioning, management, and in optimal conditions, they are management, environment, strategy, marketing mix, segmentation, target market and positioning.

In the existing situation, using regression estimates and their significant test for the effect of different factors, the results of path analysis were as follows in Figure 1.

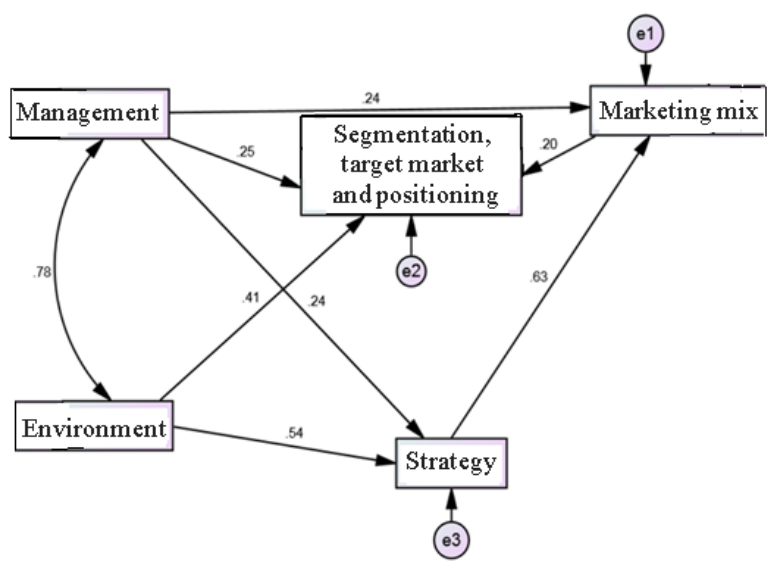

Figure 1. Path Analysis Model for the existing Status

In optimal conditions, using regression estimates and their significant test for the effect of different factors, the results of path analysis were shown in the following model in Figure 2.

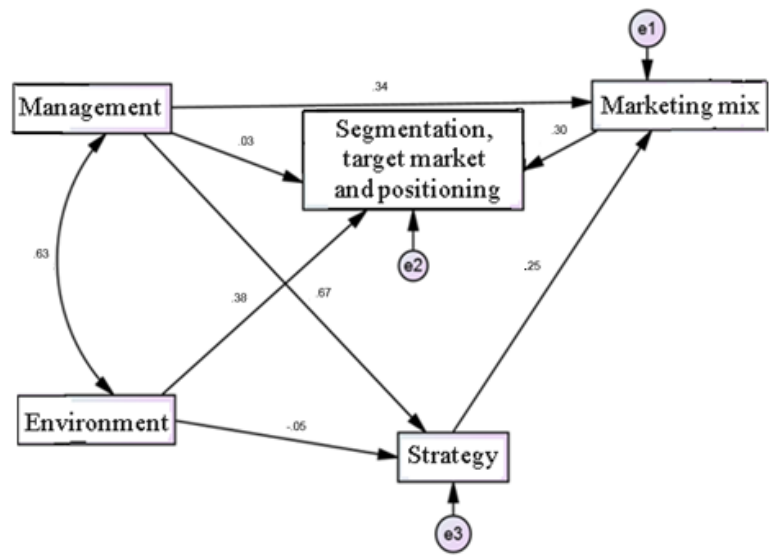

Figure 2. Path Analysis Model for Optimal Situation

Table 2. The Results of the Kolmogorov-Smirnov Test to verify the Normal Distribution of Scores

\begin{tabular}{|c|c|c|c|}
\hline & k-s & Level Significant & Number \\
\hline \multicolumn{4}{|l|}{ Management } \\
\hline Current status & 0.684 & 0.737 & 102 \\
\hline Desirable situation & 0.710 & 0.695 & 102 \\
\hline \multicolumn{4}{|l|}{ Environment } \\
\hline Current status & 0.888 & 0.409 & 102 \\
\hline Desirable situation & 0.744 & 0.637 & 102 \\
\hline \multicolumn{4}{|l|}{ Strategy } \\
\hline Current status & 0.845 & 0.473 & 102 \\
\hline Desirable situation & 1.201 & 0.112 & 102 \\
\hline \multicolumn{4}{|c|}{ Segmentation, target market and positioning } \\
\hline Current status & 1.291 & 0.068 & 102 \\
\hline Desirable situation & 1.242 & 0.092 & 102 \\
\hline \multicolumn{4}{|l|}{ Marketing mix } \\
\hline Current status & 0.973 & 0.301 & 102 \\
\hline Desirable situation & 0.741 & 0.642 & 102 \\
\hline
\end{tabular}


Table 3. Results of Single Sample t-Test to Assess the Variables in the Optimal Situation

\begin{tabular}{|c|c|c|c|c|c|c|c|}
\hline \multirow[t]{2}{*}{ Variable } & \multicolumn{7}{|c|}{ Test value } \\
\hline & Number & Average & $\begin{array}{l}\text { Standard } \\
\text { deviation }\end{array}$ & $\mathbf{T}$ & $\begin{array}{c}\text { Degrees of } \\
\text { freedom }\end{array}$ & $\begin{array}{c}\text { The } \\
\text { significance } \\
\text { level }\end{array}$ & $\begin{array}{c}\text { The mean difference of } \\
\text { the variable with the test } \\
\text { value }\end{array}$ \\
\hline management & 102 & 4.46 & 0.24 & 62.272 & 101 & 0.000 & 1.46 \\
\hline environment & 102 & 4.25 & 0.24 & 52.670 & 101 & 0.000 & 1.25 \\
\hline Strategy & 102 & 4.51 & 0.33 & 46.879 & 101 & 0.000 & 1.51 \\
\hline $\begin{array}{l}\text { Segmentation, target } \\
\text { market and positioning }\end{array}$ & 102 & 4.32 & 0.32 & 41.423 & 101 & 0.000 & 1.32 \\
\hline Marketing mix & 102 & 4.44 & 0.28 & 52.431 & 101 & 0.000 & 1.44 \\
\hline
\end{tabular}

Table 4. Factor Load of Variables affecting Marketing in the desired and existing Situation

\begin{tabular}{|c|c|c|c|}
\hline \multicolumn{2}{|l|}{ Current status } & \multicolumn{2}{|l|}{ Desirable situation } \\
\hline Variable & Factor load & Variable & Factor load \\
\hline management & 0.924 & management & 0.867 \\
\hline environment & 0.892 & environment & 0.748 \\
\hline Strategy & 0.872 & Strategy & 0.743 \\
\hline Segmentation, target market and positioning & 0.868 & Segmentation, target market and positioning & 0.708 \\
\hline Marketing mix & 0.859 & Marketing mix & 0.684 \\
\hline \multicolumn{2}{|c|}{ The value of the explained variance is 78.04} & \multicolumn{2}{|c|}{ The value of the explained variance is equal to 56.65} \\
\hline
\end{tabular}

\section{DISCUSSION}

As mentioned above, the present article aims at designing and developing a marketing model for Iranian volleyball super league clubs. In the results, it was observed that in the current situation, the priority of the Iranian super volleyball league marketing variables is environment, marketing mix, strategy, segmentation, target market and positioning, and management. In the desired situation, the priority of the volleyball league marketing variables in Iran is management, environment, strategy, marketing mix, segmentation, target market and positioning.

Also, in assessing the available and desirable position through regression and path analysis, the existing and desired status model was obtained. In a previous research, factors affecting marketing have been investigated and the managerial factor has been considered as an effective element in marketing.

In today's society, any sports organization should be able to cope with change if it seeks to be alive and successful. It is important to understand the need for change, taking into account the aspects of the permanent change of society, for both the heads of sports organizations and the sports personnel who are ready to take professional training for the future management of the sport. Managers should have deep knowledge and a wide range of special competencies $(2,11)$.

Another research results on sport marketing analysis showed that if the league is looking for success and development, then the league management should first identify and neutralize the deterrent factors. In this research, the effective factors and identifying suitable managerial strategies for the marketing of such a competition have been emphasized (14).

The results of another research suggest that the strategy component is one of the effective factors in marketing. In marketing strategy, companies and various sports organizations, through the design and implementation of appropriate marketing mixing elements according to the needs and demands of potential customers in that target market, seek to gain competitive advantage and create synergy.

In the economic situation of our country, and in light of the new economic policies of sport, sports teams should be able to maintain their competitive power through marketing strategies (15). Research results that investigated the positioning factor as an effective factor in marketing showed that organizations that do not have a specific pattern of decision making and a proper understanding of the market and competition are excluded from the competition cycle. The results of other studies also indicate that institutions that do not use a clear and comprehensive strategy for positioning in the market and the target sector do not perform well. Therefore, for the volleyball league, it is essential for the market that they want to invest first to obtain clear and explicit information and knowledge in order to obtain the desired results.

Based on the priority of the factors influencing the marketing of Iranian volleyball league in this research, management, environment, strategy, segmentation and marketing mix were ranked as the most and the least priority. The managerial 
factor in the present study was prioritized as the most important factor among the five factors.

A group of experts believe that marketing managers of the National Olympic Committee and sports federations should consider several factors in their goals, which are the most important factors in managing (3). An environment that governs an organization of sport, any decision of the government and legislation in various fields, regulations, the monetary and tax system, the transversal system, the interruption of political relations, competition, population, income, and even the climate, climatic and indigenous conditions affect the system of sports markets and their components. These effects may be very deep or partial.

The most important feature of the environment is change. In these transformations there are opportunities, threats and dangers that the sports marketer must study, evaluate, and apply the most opportunities and minimize threats and risks. In order to better understand the environmental factors, they must be identified and evaluated and collected and analyzed. Knowing the environment and positioning makes it possible for the sports marketer to recognize opportunities and create markets for them better and faster (16).

\section{CONCLUSION}

The results of this study also show the sport marketing environment in segmentation, target market and sport marketing position. It was also shown that there is a significant positive relationship between sport marketing environment and sport marketing management; there is a significant positive relationship between sport marketing environment and sport marketing strategy; in optimal situation, sport marketing environment has no significant effect on sport marketing strategy. Sports marketing mix is a controllable element that sports marketer has to achieve. In the present study it was shown that sports marketing mix has a positive effect in segmentation and positioning in sports marketing. That is, the marketer affects segmentation, target market, and marketing position by using marketing mix elements that include product, price, promotion, distribution, individuals, physical evidence and public relations.

Sports marketing manager is responsible for the market management and sports customer for the ultimate sports product. Market research managers are responsible for scheduling, promotion and public relations managers are responsible for official marketing work in sports organizations. According to the results of this study, sport marketing management has a significant positive effect on sport marketing strategy; also, sport marketing management has a significant positive effect on segmentation, target market and sport positioning.

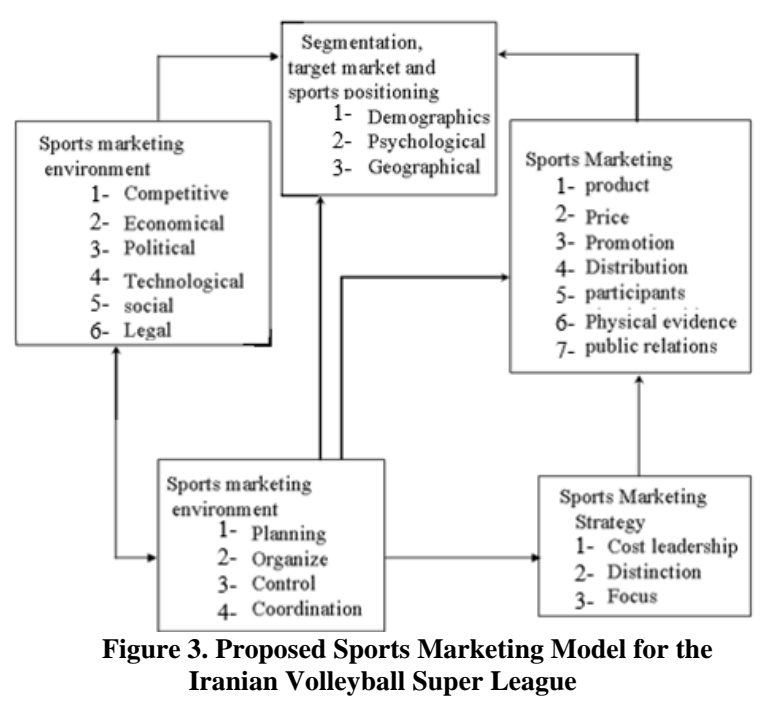

In optimal situation, sport marketing management has no significant effect on segmentation, target market and sport positioning. Research conducted to date in the field of sports marketing in Iran, such as the present study, did not mention 5 factors in their research. The exploratory model of the marketing mix of the sports industry in Iran; the marketing strategies for the promotion and development of sports fields in Iran (including public sport and heroism) have examined environmental factors; however, the present study, in a wider sense, identified several factors, and presented a model for marketing in the Iranian volleyball super league for, as follows.

\section{APPLICABLE REMARKS}

According to the latest direct and indirect relationships between the variables and the modifications made in the model, we can propose the following model for the marketing of the volleyball league in Iran:

- It is suggested that considering the fact that management factor is one of the most important elements in marketing in 
volleyball, it is necessary for the managers to train before and during management training to enhance their knowledge of business strategy based on reducing costs and improving quality and product innovation.

- It is also recommended that the volleyball federation and provincial committee members form an effective and strong market presence in order to obtain the necessary information and create a strong database in the field of positioning and market segmentation of the market and provide the necessary solutions for the effective presence of this sport in the market.

- It is suggested that managers and officials take the necessary coordination between the Ministry of Sports, the Volleyball Federation and the League in order to overcome the gap between the current and desirable factors affecting marketing.

\section{REFERENCES}

1. Hsu M, Yoon C. The Neuroscience of Consumer Choice. Curr Opin Behav Sci. 2015;5:116-121. doi: 10.1016/j.cobeha.2015.09.005 pmid: 26665152

2. Ehsani M. New Sports Marketing Patterns. In: Shiraz, editor. 1st National Marketing and Management Seminar of Shiraz2015.

3. Danesh Sani K, Safania AM, Poursoltani H. Identification and Prioritization of Factors Affecting Neuromarketing in Sport Based on Analytical Hierarchy Process (AHP). Neurosci J Shefaye Khatam. 2017;5(3):35-43. doi: 10.18869/acadpub.shefa.5.3.35

4. Bauer HH, Stokburger-Sauer NE, Exler S. Brand Image and Fan Loyalty in Professional Team Sport: A Refined Model and Empirical Assessment. J Sport Manag. 2008;22(2):205-226. doi: 10.1123/jsm.22.2.205

5. Ghanbari M, Dehghan S. The Effect of Green Marketing Strategy on Organizational Performance in Sport Federations. J Sci Eng. 2018;3(6):28-38.

6. Memari J. Modeling and analysis of marketing mix of sport industry in the country (with decisioncentered approach). Tehran Tehran University; 2007.

7. Hosseini S. Determining the Marketing Model of the Football League of the Islamic Republic of Iran. Tehran: Tarbiat Modarres University; 2012.

8. Atghia N. Marketing and Management Interaction. Quarterly Journal of Sport Sciences. Iran: Institute of Physical Education and Sport Sciences Ministry of Science, Research and Technology, 2002.

9. Kast M. Professional Team Sports Marketing, A comparative view on UK and US marketing approaches - exemplified by the FA Carling Premier league Football and the National Basketball Association. Manchester University of Manchester Institute for Science and Technology Manchester School of Management, 2012.

10. Shank M. Sport Marketing a Strategic Perspective. Saddle River, NJ: Prentice Hall; 2013.

11. Shamsipour S. Investigation of customer acquisition strategies by specially designed bodybuilding salons for women in Isfahan. 1st National Marketing and Management Seminar of Shiraz; Shiraz2004.

12.Islamic Republic of Iran Physical Education Organization. Combined studies of the strategy document for the development of the comprehensive system of physical education and sport. Tehran: Publications of the Digital Library of Tehran University; 2005.

13. Forneris T, Camiré M, Trudel P. The development of life skills and values in high school sport: Is there a gap between stakeholder's expectations and perceived experiences? International Journal of Sport and Exercise Psychology. 2012;10(1):9-23. doi: 10.1080/1612197x.2012.645128

14.Lin RJ, Chen RH, Kuan-Shun Chiu K. Customer relationship management and innovation capability: an empirical study. Industrial Management \& Data Systems. 2010;110(1):111-133. doi: 10.1108/02635571011008434

15.Robinson CK. Peter Drucker on marketing: application and implications for libraries. The Bottom Line. 2012;25(1):4-12. doi: 10.1108/08880451211229153

16. Hosseini SM, Nekouizadeh M. Analysis of Marketing Strategies for Service Companies during the Depression. J Busin Manag Outlook. 2011;10(6):117-139. 